\title{
Sleep Forensics: a critical review of the literature and brief comments on the Brazilian legal situation
}

\author{
Medicina do sono Forense: uma revisão crítica da literatura e breves comentários sobre a \\ situação brasileira \\ Raimundo Nonato Delgado-Rodrigues ${ }^{1}$, Alexander N. Allen², Leandro Galuzzi dos Santos ${ }^{3}$, Carlos H. Schenck
}

\begin{abstract}
Sleep medicine is a relatively new field among Medical Sciences. Its legal aspects are still obscure, either for lack of knowledge of the biological mechanisms underlying violent behaviour during sleep or the virtual absence of clear legal and uniformly accepted guidelines as to whether to punish or treat those disorders. An updated review of the pertinent literature was performed to determine the most prevalent pathological conditions involving violence and sleep and to identify their most common precipitating factors, attempting to provide some technical support to aid Brazilian medical-experts or assistants in preparing substantial and scientific-based reports in a legal environment.
\end{abstract}

Keywords: sleep medicine, sleepwalking, behaviour disorder, parasomnia.

\section{RESUMO}

A medicina do sono é um campo relativamente novo dentro das Ciências Médicas. Seus aspectos legais encontram-se ainda na obscuridade, seja por falta de conhecimento dos mecanismos biológicos do desenvolvimento dos transtornos de comportamento e da violência praticada em estados alterados de sono, seja por virtual ausência de previsão legal do binômio tratamento/punição. Realizamos revisão atualizada da literatura para determinar as condições patológicas mais prevalentes envolvendo violência e sono, identificar seus fatores precipitantes mais comuns e os critérios médico-legais que podem auxiliar eventuais médicos-peritos ou assistentes na elaboração de pareceres abalizados em âmbito legal.

Palavras-chave: medicina do sono, sonambulismo, transtorno de comportamento, parassônia.

While the idea of violent acts committed by an unwilling assailant in the throes of sleep has been recorded as early as the 1200s, it was not until 1686 that documentation for an English legal case was found. Colonel Cheyney Culpepper, a known and habitual sleepwalker, shot an officer of the guard with a blunderbuss ${ }^{1}$. He was first found insane at the Old Bailey, but then later pardoned by James II. From this point on, there were few legal cases using the sleep state as a defence, with none in the 1700s, no doubt in part due to the scepticism of the public and, indeed, of the scientific community at the time, as to the legitimacy of these conditions ${ }^{2}$.

More cases began to spring up in the 1800s, partially attributed to the increase in newspaper circulation both in
America and Europe, and the sensationalist stories of sleepwalkers becoming more popular with the general public. While physicians were aware of somnambulism and its potential for violence, and considered it a genuine disorder as early as the 1840s, they were generally informed only by their own experiences and single case reports ${ }^{3}$. Their testimonies were not always enough to sway a jury, with English psychiatrist John Pagan exclaiming "It would be exceedingly difficult to convince a jury of the real existence of such a condition"4. At this time, in the view of the public, sleepwalking was considered eccentric rather than malignant, and for the most part harmless. It was not until the $20^{\text {th }}$ century, when the speciality of sleep medicine was founded, that robust scientific

\footnotetext{
'Professor of Neurology, MD, PhD, Centro de Distúrbios do Sono, Hospital Universitário de Brasília, Universidade de Brasília, Brasília DF, Brazil; ${ }^{2} \mathrm{BA}, \mathrm{BMBCH}$, Foundation Doctor, North Central Thames Foundation School, London, England;

${ }^{3} J u d g e$ of Instruction Brazilian Supreme Court, Brasília DF, Brazil;

${ }_{4}^{4 M D}$, Professor of Psychiatry, University of Minnesota, Minnesota Regional Sleep Disorders Centre, Minneapolis, USA.

Correspondence: Raimundo Nonato Delgado-Rodrigues, SQN 206 Bloco K apt. 303, CEP: 70844-110 Brasília DF, Brasil. E-mail: reno@unb.br

Received 24 June 2013; Received in final form 09 August 2013; Accepted 16 August 2013.
} 
evidence and expert witnesses could be used to inform the legal proceedings in cases such as these.

With psychiatry only emerging as a field of research in the early 1800s, the phenomenon of sleep, and the disturbances that could potentially cause these violent outbursts, was not formally studied until the $20^{\text {th }}$ century. The electroencephalogram (EEG) was used to describe cerebral activity during sleep and wakefulness in 1923. REM (Rapid Eye Movement) sleep cycles were first described in 1953, modern sleep laboratory techniques were used to study sleepwalking and sleep apnoea in 1964 and 1965, with REM sleep disorders finally being described in $1985^{5}$. As a result, there has been an increase in the number of cases where sleep behaviour disorders were used as a defence, relying heavily on expert witnesses.

\section{The disorders}

The types of sleep disturbances that can lead to criminal behaviour, whether violent or sexual, are known as parasomnias and can be classified into six main categories:

(1) Non-rapid Eye Movement (NREM) disturbances of arousal describes a spectrum ranging from confusional arousals (sometimes known as sleep drunkenness) to sleep terrors, and includes sleepwalking (SW), with or without the performance of complex behaviours. These events can begin in adulthood or be continued from childhood, and, in most cases, do not indicate significant psychiatric pathology? They are in fact fairly common, with some studies indicating that as many as $3-4 \%$ of the general population may suffer from these episodes in some form ${ }^{8}$. Treatment is both pharmacological, using sedatives such as benzodiazepines and tricyclic antidepressants, and psychological, with hypnosis being shown to be effective in some cases.

Recently, reports of sexual parasomnias, commonly known as sleep-sex or sexsomnia, have been published ${ }^{10,11}$. These conditions occur while an individual is sleeping and include sexually oriented behaviour, including attempts to have intercourse with their partner or even objects, often with a certain degree of aggression and violence, obscene language, or even masturbatory activity. This behaviour is generally quite opposite to the patient's habitual wakeful characteristics.

It is also worth mentioning recent reports of "parasomnia pseudo-suicide", in which some individuals perpetrate fatal aggressions against themselves during a parasomnia-related automatism episode. The legal as well as insurance implications may be enormous ${ }^{12}$.

(2) Rapid Eye Movement (REM) sleep behaviour disorder $(R B D)$ is thought to arise due to a failure in the REM sleep muscle atonia. Without this sleep-induced atonia, dreams can be enacted, and if these dreams involve extensive physical activity or a violent act, they can very easily lead to injury to both the patient and the unfortunate bed partner. Interestingly enough, REM sleep disorders can be a symptom of synucleinopathies (diseases caused by inclusions of the protein a-synuclein), such as Parkinson's disease, Lewy body dementia and multiple system atrophy. The sleep disturbance can precede the motor or cognitive symptoms of the disease by over ten years; therefore all patients suffering from RBD should be kept under regular review by a neurologist, who should be vigilant for any decline in cognition or motor function $^{13}$. Approximately $90 \%$ of those who suffer from RBD are male ${ }^{14}$, leading to various hypotheses that sexual hormones may play a role, either in the failure of muscle atonia during sleep, or in a propensity to violent dreams ${ }^{15}$. However, one controlled study did not find any difference in the serum level of sex hormones between men with RBD and controls ${ }^{16}$, leaving these hypotheses currently unproven. RBD can be very hard to distinguish from disturbances of arousal described above, on clinical grounds without video-polysomnography.

(3) Seizures causing nocturnal violence normally originate from a frontal focus, causing disinhibition and violent thrashing motions. Temporal seizures have also rarely been noted to be a cause of sleepwalking and night time violence ${ }^{17}$. The violence can occur during the prodromic phase, the seizure itself or in the post ictal period. These events unhelpfully often lack the classic signs of epileptic seizures, such as tongue biting, post-ictal confusion, loss of consciousness, incontinence, and even EEG abnormalities ${ }^{18}$. Treatment with the standard array of anti-seizure medications can often be effective. Due to the non-standard presentation of these seizures, they can often be indistinguishable from other sleep disorders.

(4) Psychogenic nocturnal dissociative states are well recognised as occurring in the awakened state, often leading to unexplained behaviour such as traveling a long distance, and are associated with amnesia and violence ${ }^{19}$. It has also been described that such states could occur with the patient seemingly asleep on behavioural observation for the entire episode, even though they have sustained EEG wakefulness. Therefore, these episodes demonstrate a dissociated state of wakefulness emerging during the sleep pe$\operatorname{riod}^{20}$. Patients suffering from these states almost always have a history of childhood violence or sexual abuse, and due to the amnesia associated with these states, are normally unaware of their condition. Treatment involves psychotherapy aimed at the precipitating cause.

(5) Münchausen syndrome by proxy is a condition in which a child is reported to have apparently serious medical symptoms that are in actuality induced by an adult, usually a caregiver and often a parent. These symptoms may range from reported nocturnal seizures or unusual spells, to sleep apnoea episodes, daytime sleepiness, etc. Diagnosis is a complex matter and often requires careful video-polysomnographic (video-PSG) monitoring, with a parent or other caregiver present, to document the actual cause of the reported symptoms ${ }^{21,22}$. For example, in one case of reported sleep apnoea, the mother of a child was documented by video-PSG to repeatedly attempt to suffocate the child with a pillow ${ }^{23}$. 
When the correct diagnosis is found, child protection agencies should be notified immediately to protect the child, while the adult perpetrator needs to be taken into custody and also undergo a psychiatric evaluation.

(6) Malingering is the deliberate and false representation or the faking of a symptom (or suggestive parasomnia state) for personal benefit, frequently criminal. Defence against charges of homicide intent would be an appropriate example. Obviously, the perpetrator having parasomnia antecedents will increase inherent difficulties in providing definite diagnosis.

\section{Diagnostics and Triggers}

These conditions, particularly RBD and NREM disorders are usually easy to diagnose with the combination of clinical evaluation and video-PSG. A full medical and psychiatric history must be taken, including corroboration from bed partners and/or family members, which may point towards the diagnosis of a parasomnia. However, as mentioned above, taken alone it may not pinpoint the specific type of disorder, and without this knowledge further management and prognosis of the patient cannot be determined. Therefore a full patient assessment should include sleep laboratory studies, including electroencephalogram and respiratory function monitoring during sleep, carried out by trained sleep specialists. Obviously if the patient has an episode during the study the diagnosis is straightforward, but life is rarely that easy.

Consequently there has been much research into what factors can contribute to parasomnias, particularly those that can be detected during "normal" sleep. This is particularly true for slow wave sleep activity and the NREM sleep parasomnias, as described below.

Slow wave sleep (SWS), or NREM sleep stage N3 was thought in the past to have been associated with sleepwalking, as it was noted to comprise a higher percentage of total sleep in children, which happens to match the age distribution of the incidence of sleepwalking[24]. However this theory has not held up to scientific scrutiny, as less than half the sleep studies show an increase in SWS in sleepwalkers ${ }^{24}$.

Analysis of the SWS brain activity itself reveals a potential difference between sleepwalkers and controls, showing decreased delta activity power ${ }^{25}$. However, as these SWS abnormalities are also present during nights when sleepwalking episodes do not occur, SWS power spectrum analysis cannot discriminate between sleepwalkers and controls. By the same token, abnormal SWS activity alone is not enough to trigger an episode and other such triggers may be necessary, such as frequent SWS arousals. This has led to the idea that arousal disorders are due to NREM sleep instability ${ }^{26}$. To put it in another way, the repeated arousals would concur to sleep fragmentation and ultimately cause a sleepwalking episode. A higher SWS proportion would only provide a greater window of opportunity in which these arousals can occur. It is worth noting that studies have pointed out that patients with other nocturnal disturbances, such as obstructive sleep apnoea or periodic leg movements, can show a similar pattern of arousals without resulting in sleepwalking ${ }^{27}$.

For RBD, the American Academy of Sleep Medicine provides a scoring system to assist in the diagnosis of RBD, primarily based on video-PSG monitoring and sustained or multiple episodes of muscle activation, as measured by electromyography (EMG), while in the REM sleep phase. This has recently been updated in the upcoming International Classification of Sleep Disorders, $3^{\text {rd }}$ Edition (ICSD-3) to be published in 2013, for which one of the authors (CHS) served as a member of the Parasomnias Committee for updating the RBD diagnostic criteria. Objective documentation of "REM sleep without atonia" is essential for diagnosing RBD. Recently, the SINBAR Group (Sleep Innsbruck Barcelona) published normative values for EMG detection in RBD and suggested that using the mentalis and right/left flexor digitorum brevis muscles with a cut-off value of $32 \%$, using 3 -second mini-epochs, or $27 \%$, using 30 -sec epochs, would improve the diagnostic accuracy for either idiopathic or secondary RBD, in regards to distinguishing RBD patients from controls $^{28}$. The essential diagnostic criteria for RBD (ICSD-3) include the following: A. Repeated episodes of sleep-related vocalization and/or complex motor behaviors. B.These behaviors are documented by PSG to occur during REM sleep or, based on clinical history of dream enactment, are presumed to occur during REM sleep. C. PSG recording demonstrates REM sleep without atonia. Furthermore, bilateral EMG detection on the anterior tibialis muscles could be useful for periodic leg movement detection in REM and NREM sleep that is common with RBD.

Genetic predisposition is an important contributing factor, the risk of sleepwalking or similar disorders being increased tenfold if a first-degree relative is affected ${ }^{29}$. A key feature appears to be the presence of the HLA-DQB1 haplotype identified in $35 \%$ of sleepwalkers, in a small series, compared to $13.3 \%$ of those not so affected ${ }^{30}$.

Medications can also often play a role in inducing parasomnias, although there are no controlled studies. The range of medications that can induce episodes is large, and includes most types of psychotropic drugs ${ }^{31}$.

Alcohol as a trigger for sleepwalking is a contentious issue. It is often used as a legal defence because acute severe alcohol intoxication can cause behaviours similar to a parasomnia. Nevertheless, the individual is legally considered sane. Studies have also shown that both chronic alcoholics and those who are abstaining from alcohol show some EEG findings (reduced SWS and REM stage sleep) that curiously could decrease their likelihood of sleepwalking ${ }^{32,33}$. From a forensic perspective, there is no validity in claiming SW for a legal episode in which there was alcohol intoxication. In other words, alcohol intoxication disqualifies the use of a parasomnia (SW, RBD, etc) defence in a criminal trial ${ }^{34}$. On the 
other hand, modest alcohol consumption can be a trigger for SW episodes but, ideally, that should be identified clinically or by family/friend corroboration. In a criminal trial, modest alcohol use as a trigger for a SW episode, with forensic consequences, can be considered as a possibly valid parasomnia (SW) defence. Furthermore, sleep fragmentation secondary to alcohol intake (even in modest amounts) can promote arousals that trigger NREM parasomnia episodes.

Sleep deprivation, resulting in an increase in SWS and increased arousals, is well known to be associated with sleepwalking episodes. This has been partly shown experimentally in several studies where both sleepwalkers and controls were sleep deprived. While all studies showed an increase in SWS, one showed a decrease in sleepwalking ${ }^{35}$. This may have been due to a difference in study design, as this study had a longer period of the sleep deprivation, indicating there may be a "window" of sleep deprivation in which patients both experience increased SWS and are able to respond to other triggers for their parasomnia.

Finally, physical stimuli have been reported to trigger parasomnia episodes, including fevers ${ }^{36}$, sudden touch and loud noises ${ }^{37}$. These triggers may be used as a way of initiating sleepwalking episodes in the sleep laboratory setting. A study using repetitive auditory stimulation and sleep deprivation easily induced sleepwalking in those with a known history ${ }^{38}$.

Further to this, some research has tried to identify differences between those patients who experience parasomnias resulting in violent activity and those who do not. Studies have shown little difference between these two groups, beyond a predisposition to male gender in the violent group, possibly representing a role for sex hormones or just the increased physical ability male's possess to harm ${ }^{39}$. What is made clear, however, is that all those who had violent nocturnal episodes had previously experienced many non-violent episodes which were usually simply accepted by family and friends and rarely mentioned to a doctor, reinforcing the view that the public consider parasomnias a benign condition ${ }^{39}$.

\section{Medico-legal issues}

The variety of cases where forensic Sleep Medicine is pertinent ranges from the tragic, (a man thinking he was defending his child against a wild beast but ended up killing him) to those that would not be out of place in a crime thriller novel (a detective, taking a holiday after solving a particularly gruesome case, is called out to investigate a murder on a beach. He correctly concludes that he himself must have committed the crime while sleepwalking $)^{40}$.

Despite the advances in defining the scientific basis of sleep, the medico-legal aspects of sleep medicine are still somewhat unclear. Even with a positive diagnosis, no easy task itself, this does not prove that the suspect was undergoing a parasomnia episode at the time of the criminal action. As there is an obvious advantage to the defendant claiming they had no control over their actions, there has been much debate as to how to distinguish true cases of parasomniainduced violence from conscious actions. There are several guidelines available ${ }^{41-43}$, and most agree on the salient points: (a) previous history of parasomnia or at least truthful reports or sleep laboratory findings of similar (or not so similar) episodes; (b) the victim should have only been present by coincidence rather than being targeted; (c) a feeling of horror and guilt should be apparent once consciousness returns, with no attempt to escape or cover up the deed; (d) there should normally be some degree of amnesia regarding the event (or, in case of RBD, recalling vivid/violent dreams) and (e) the crime is out of character for the person in question. These factors are combined with the potential triggers listed above to assess the likelihood of a genuine parasomnia episode.

Of course there are still many legal questions that remain beyond the identification of parasomnia, for example, if a patient is aware of their condition, how far should they go to prevent a violent episode? Some obvious measures such as making sure doors are locked and weapons are not at hand or yet using of door alarms (bedroom, front door) could be an inexpensive and important intervention for aborting parasomnia SW episodes. However, what about those sleeping alone? Should patients have to inform those that sleep in the same house about their condition? This could have a potential impact on the social and psychological aspects of patients' lives, when it is quite possible they would never have a violent episode. This appears to be an area where the science of sleep medicine will be able to guide the law and legal implications as more about the risks, the triggers and the treatments become known.

The determination of sanity, consciousness of the act during a parasomnia episode and, consequently, accountability for the criminal act are still a matter of much debate in countries where the medical and legal structures allow an adequate approach of parasomnia-related violence cases.

After careful examination of many legal reports from the American and Canadian courts, Schenck et al. ${ }^{6}$, criticized the legal notion that sleepwalking with a high rate of recurrence be considered an "insane automatism". According to these authors, this would grant an open-ended confinement in mental hospitals for those who commit violent acts during a state of somnambulism, if the existence of a high probability of recurrence was determined. Furthermore, the law would not, at any moment, grant those people specialized treatment in a Sleep Medicine Centre or consider that treatment could successfully change the patient's legal status (converting it to a "non-insane automatism") once the possibility of recurrence was reduced. By the same token, no provision for accountability is made for the individual who, having been advised of their risk factors for initiating a sleep automatism, would deliberately seek exposure to such situations in order to commit a crime and grant a favourable legal defence of "non-insane automatism". 
Thus, the afore-mentioned authors not only suggest that parasomnia with continuing danger be considered a "noninsane automatism" but also introduce the concept of "intermittent state-dependent recurring danger" ${ }^{6}$. Such a concept helps determine the future accountability of someone who has just been acquitted by using the "parasomnia state" defence. Through clinical assessment, possible trigger factors for that parasomnia would be identified and the defendant advised to avoid such triggers. Otherwise, sleepwalking would be unacceptable as a defence argument if another violent episode of parasomnia due to the same trigger should recur in the future. Nevertheless, the recklessness of engaging in a risky behaviour should be firmly determined. For instance, if it is already known that sleep deprivation for a certain subject is a trigger factor for automatisms, but this particular individual is a caregiver and on a certain occasion was forced to spent their precious sleep hours caring for someone gravely ill, if they present a violent episode of parasomnia, this person should not be considered accountable for their acts ${ }^{6}$.

The Brazilian situation is more difficult to analyze, as Sleep Medicine in our country is not yet considered a specialty, in spite of recent efforts to consider it a "field of expertise” in Neurology, Psychiatry, ENT (Ear-Nose and Throat), and Pneumatology residency programs. Furthermore, there is an inadequate number of sleep centres to attend our Public Health System and insufficient expertise on the matter under discussion.

The Brazilian Penal Code (Parte Geral, Título III) dating from the late 40s, when discussing the necessary conditions for determining legal unaccountability, establishes that the individual is exempt of punishment who, by reason of mental illness or "incomplete cerebral development or retardation", and is, at the time of the crime, entirely unable to understand the illicit nature of the fact ${ }^{44}$.

Still, according to Brazilian Law, sleepwalking is considered a mental disease since it is registered in the DSM IV (Diagnostic and Statistics Manual of Mental Diseases). However, the Brazilian Penal Code also considers unaccountable those suffering from epilepsy, narcolepsy or even those in a hypnotic state (whatever that may mean) ${ }^{45}$. According to Brazilian Legislators, such states could be associated with an impairment of the individual's ability to act on their own volition ${ }^{46}$.

There are few, if any, reports of parasomnia being used as a defence argument in Brazilian Courts. Existing jurisprudence seems to be based on outdated, or even non-scientific, medical concepts. There is no Sleep Forensics expertise or legal provision for a mandatory, systematic and scientific evaluation of the defendant's sleep patterns.

It is still unfortunate that in our country, in spite of the gigantic number of crime reports and diversity of legal cases, there is no scientific research on their original causes. Thus, the parasomnia defence argument, accepted or not by Brazilian judges, is not to be found, whether for lack of historical documentation, so characteristic of our society, or the lack of adequate structure in our court system or universities to sponsor such studies. Indeed, murder, sexual violence, physical aggression and a diverse series of crimes, when perpetrated by individuals in a disordered state of sleep, may be registered only as a "homicide", "rape", "bodily injury", etc. This situation prevents a more accurate study of the legal position of Brazilian Courts concerning these types of crimes or the accountability of sleep disorder patients and the criminal relevance of their actions.

Finally, Sleep Medicine is still a relatively new field of research, and Forensic Sleep Medicine even more so. In recent years, much progress has been made in understanding the physiology behind sleep disorders, and their potential triggers. Advances have been made although diagnosis still remains a problematic issue. Clarification of the legal issues surrounding Sleep Medicine is also in its infancy. However, as the science underlying expert opinions is strengthened, hopefully this area will become clearer and, more importantly, objective and fair.

\section{Acknowledgement:}

The authors wish to thank Mr. Mark Allen Evans for the revision of the English manuscript.

\section{References}

1. Walker N. Crime and insanity in England. Edinburgh (United Kingdom): Edinburgh University Press; 1968.

2. The Proceedings of the Old Bailey, 1674-1913. Available at: http:// www.oldbaileyonline.org. Accessed 06.24.2013.

3. Winslow F. The plea of insanity in criminal cases. London: Da Cap; 1843 [reprint, New York; 1983].

4. Pagan JM. The medical jurisprudence of insanity. London: Ball, Arnold \& $\mathrm{Co} ; 1840$.
5. Ekirch AR, Shneerson JM. Nineteenth-century sleep violence cases: a historical view sleep parasomnia sleep violence. Clin Sleep Med 2011;6:483-491.

6. Schenck C. Paradox lost: midnight in the battleground of sleep and dreams. $1^{\text {st }}$ Ed. Minneapolis, Minnesota, USA. Extreme-Nights, LLC, 2005.

7. Mahowald MW, Cramer-Bornemann MA. NREM Sleep dipsomanias. In: Kryger MH, Roth T, Dement WC (Eds). Principles and practice of sleep medicine. Philadelphia, PA: Elsevier/Saunders, 2005:889-896. 
8. Hublin C, Kaprio J, Partinen M, et al. Prevalence and genetics of sleepwalking: a population-based twin study. Neurology 1997;48:177-181.

9. Mahowald MW, Schenck CH. NREM sleep parasomnias. Neurol Clin 2005;23:1077-1106.

10. Schenck $\mathrm{CH}$, Arnulf I, Mahowald MW. Sleep and sex: what can go wrong? A review of the literature on sleep related disorders and abnormal sexual behaviors and experiences. Sleep 2007;30:683-702.

11. Ariño H, Iranzo A, Gaig C, Santamaria J. Sexsomnia: parasomnia associated with sexual behaviour during sleep. Neurologia 2013 May 7. pii: S0213-4853(13)00019-4. doi: 10.1016/j.nrl.2013.01.013. [Epub ahead of print]

12. Mahowald MW, Schenck CH, Goldner M, Bachelder V, CramerBornemann M. Parasomnia pseudosuicide. J Forensic Sci 2003;48:1158-1162.

13. Boeve BF, Silber MH, Ferman TJ. REM sleep behavior disorder in Parkinson's disease and dementia with Lewy body disease. J Geriatr Psychiatry Neurol 2004;17:146-157.

14. Schenck CH, Hurwitz TD, Mahowald MW. REM sleep behavior disorder: a report on a series of 96 consecutive cases and a review of the literature. J Sleep Res 1993; 2:224-231.

15. Goldstein M. Brain research and violent behavior. Arch Neurol 1974; 30:1-34.

16. Iranzo A, Santamaria J, Vilaseca I, de Osaba MJ. Absence of alterations in serum sex hormones in idiopathic REM sleep behavior disorder. Sleep 2007;30:803-806

17. Guilleminault C, Silvestri R. Disorders of arousal and epilepsy during sleep. In: Sterman MB, Shouse MN, Passowant PP (Eds). Sleep Epilepsy 1982:513-531.

18. Schenck $\mathrm{CH}$. Parasomnias - clinical features and forensic implications. Contemp Rev Sleep Med 2006;130:605-610.

19. McCaldon RJ. Automatism. Can Med Assoc J 1964;91:914-920.

20. Schenck CS, Milner DM, Hurwitz TD, et al. Dissociative disorders presenting as somnambulism: polysomnographic, video, and clinical documentation (8 cases). Dissociation 1989; 4:194-204.

21. Mahowald MW, Schenck CH, Rosen GM, Hurwitz TD. The role of a sleep disorder center in evaluating sleep violence. Arch Neurol 1992;49:604-607.

22. Griffith JC, Slovik LS. Munchausen syndrome by proxy and sleep disorders medicine. Sleep 1989;12:178-183.

23. Light MJ, Sheridan MS. Munchausen syndrome by proxy and apnea. Clin Pediatr 1990; 29:162-168

24. Joncas S, Zadra A, Paquet J, Montplaisir J. The value of sleep deprivation as a diagnostic tool in adult sleepwalkers. Neurology 2002;26-58:936-940.

25. Guilleminault C, Poyares D,Abat F,Palombini L. Sleep and wakefulness in somnambulism: a spectral analysis study. J Psychosomatic Res 2001;51:411-416.

26. GuilleminaultC, Kirisoglu C, da Rosa AC, Lopes C, Chan A.Sleepwalking, a disorder of NREM sleep instability. Sleep Med 2006;7:163-170.

27. Pressman MR. Hypersynchronous delta sleep EEG activity and sudden arousals from slow wave sleep in adults without a history of parasomnias: clinical and forensic implications. Sleep 2004;27:706-710.
28. Frauscher B, Iranzo A, Gaig C, et al. SINBAR (Sleep Innsbruck Barcelona) Group. Normative EMG values during REM sleep for the diagnosis of REM sleep behavior disorder. Sleep 2012;35:835-847.

29. Kales A, Soldatos CR, Bixler EO, Ladda RL, Charney DS, Weber G. Hereditary factors in sleepwalking and night terrors. Br J Psychiat 1980;137:111-118.

30. Lecendreux M, Bassetti C, Dauvilliers Y, Mayer G, Neidhart E, Taft M. HLA and genetic susceptibility to sleepwalking. Mol Psychiatr 2003;8:114-117.

31. Guilleminault C, Leger D, Phillip P, Ohayon MM. Nocturnal wandering and violence: review of a sleep clinic population. J Forensic Sci 1998;43:158-163.

32. Johnson LC, Burdick J, Smith J. Sleep during alcohol intake and withdrawal in the chronic alcoholic. Arch Gen Psychiatr $1965 ; 22: 406-418$.

33. Skoloda TE. Sleep quality reported by drinking and non-drinking alcoholics. In: Gottheil El, (Ed). Addiction research and treatment: converging trends. New York: Pergamon Press;1979:102-112.

34. Pressman MR, Mahowald MW, Schenck CH, Bornemann MC. Alcoholinduced sleepwalking or confusional arousal as a defense to criminal behavior: a review of scientific evidence, methods and forensic considerations. J Sleep Res 2007;16:198-212.

35. Pressman MR. Factors that predispose, prime and precipitate NREM parasomnias in adults: clinical and forensic implications. Sleep Med Rev 2007;11:5-30

36. Kales JD, Kales A, Soldatos C, Chamberlin K, Martin ED. Sleepwalking and night terrors related to febrile illness. Am J Psychiatry 1979;136:1214-1215

37. Pressman MR. Disorders of arousal from sleep and violent behavior: the role of physical contact and proximity. Sleep 2007;30:1039-1047.

38. Pillon M, Montplaisir J, Zadra A. Precipitating factors of somnambulism: impact of sleep deprivation and forced arousals. Neurology 2008;70:2284-2290.

39. Guilleminault, Christian Moscovitch, Léger D. Forensic sleep medicine: nocturnal wandering and violence. Sleep 1995;18:740-748.

40. Shneerson JM, Ekirch AR. The clinical features of sleep violence in arousal disorders: a historical review sleep parasomnia sleep violence. Sleep Med Clin 2011;6:493-498.

41. Mahowald MW, Bundlie SR, Hurwitz TD, Schenck CH. Sleep violenceForensic science implications: polygraphic and video documentation. J Forensic Sci 1990;35:413-432.

42. Nofzinger EA. Homicidal behavior and sleep apnea: a case report and medicolegal discussion. Sleep 1995;18:776-782.

43. Schenck CH, Lee SA, Bornemann MAC, Mahowald MW. Potentially lethal behaviors associated with rapid eye movement sleep behavior disorder: review of the literature and forensic implications. J Forensic Sci 2009;54:1475-1484.

44. Brasil. Decree-Law 2.848, Penal Code, General Section, Title III (Decreto-Lei n². 2.848, Código Penal. Parte Geral, Título III), 07.12.1940.

45. Nucci, GS, Penal Law Manual - General Section (Manual de Direito Penal-Parte Geral), 6a Ed, Editora RT, SP, 2009.

46. Soares, OM. Penal Code for the Republic of the United States of Brazil (Código Penal da República dos Estados Unidos do Brasil). Ed facsim.: Senado Federal, Superior Tribunal de Justiça, Brasília, 2004. 